\title{
Development of high-resolution melting PCR (HRM-PCR) assay to identify native fungal species associated with the wheat endosphere
}

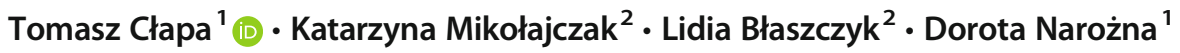 \\ Received: 20 May 2020 / Revised: 9 August 2020 / Accepted: 18 August 2020 / Published online: 23 August 2020 \\ (C) The Author(s) 2020
}

\begin{abstract}
Understanding the complexity and biodiversity of fungal communities associated with the wheat endosphere can facilitate the identification of novel strains that might be beneficial to the host plant. However, the differentiation and taxonomic classification of the endosphere-associated fungi with respect to various cultivars and plant organs are challenging, time-consuming, and expensive, even with the use of molecular techniques. In the present work, we describe a fast, simple, and low-cost method based on high-resolution melting PCR (HRM-PCR) for the identification and differentiation of wheat endogenous fungal isolates. Using this approach, we differentiated 28 fungal isolates, which belonged to five different genera, namely Alternaria, Penicillium, Epicoccum, Fusarium, and Trichoderma. Furthermore, the results of the study revealed that this method can allow large-scale screening of cultured samples.
\end{abstract}

Keywords High-resolution melting PCR · Identification assay · fungal species · Wheat endosphere

\section{Introduction}

Wheat is the second most widely grown cereal worldwide after rice. According to statistics, the global wheat production in 2017-2018 was 771.7 million tons (FAOSTAT, http:// www.fao.org/statistics/en/, 2020). Regarding quantity and the area of cultivation, wheat is the most popular among the cereals grown in the EU, accounting for nearly half of the total production of crops (EU, Eurostat, https://ec.europa.eu/ eurostat/, 2020). However, in Europe, wheat production is affected by a number of abiotic and biotic stress factors (Trnka et al. 2014). Various strategies, based on chemical, genetic, and agricultural principles, are recommended for improving the production of wheat under combined unfavorable

Communicated by: Agnieszka Szalewska-Palasz

Tomasz Cłapa

tomasz.clapa@up.poznan.pl

1 Department of Biochemistry and Biotechnology, Poznań University of Life Sciences, Dojazd 11 60-632 Poznań Poland

2 Department of Pathogen Genetics and Plant Resistance, Institute of Plant Genetics, Polish Academy of Sciences, Strzeszyńska 34 60-479 Poznań Poland environmental conditions. Among them, the use of biological control agents (BCAs) is the most promising and environmental-friendly approach. Fungi associated with the plant endosphere that live inside the plant tissues throughout or at least for a part of their life cycle without causing any disease symptoms their host are considered to be good candidates as BCAs (Rodriguez et al. 2009; Comby et al. 2016; Gdanetz and Trail 2017). The presence of these fungi, which are classified as endophytes, in wheat has already been demonstrated by several authors (Crous et al. 1995; Larran et al. 2002; Istifadah and McGee 2006; Lenc et al. 2015). Furthermore, some studies have demonstrated the possibility of colonizing cultivated wheat crops with endophytic fungi originating from other plant species and have reported the associated positive effects of those organisms. For example, certain endophytes were observed to reduce the susceptibility of wheat plants to insects and pathogens (Reddy et al. 2014; Keyser et al. 2016; Díaz Herrera et al. 2016), improve their heat and drought tolerance (Hubbard et al. 2012, 2014), and also promote growth (Colla et al. 2015). In light of this, understanding the complexity and biodiversity of fungal communities associated with the wheat endosphere can facilitate the identification of novel strains that might be beneficial to the host plant. 
In the research carried out in recent years on fungal biodiversity, molecular approaches have been favored over morphology-based methods (Schoch et al. 2012; Blaalid et al. 2013). One of the recommended approaches based on DNA sequencing for the identification of fungal species is DNA barcoding (Schoch et al. 2012; Blaalid et al. 2013). The internal transcribed spacer (ITS) region of the ribosomal DNA (rDNA) has been proposed as the official and universal DNA barcoding marker for fungi (Schoch et al. 2012; Blaalid et al. 2013). Unfortunately, this approach is not entirely practical when a large number of samples must be analyzed, for example, while exploring the diversity of the fungi associated with wheat endosphere with respect to spatial and temporal scales (different cultivars, maturity state, different plant organs), environmental factors (controlled and field-realistic growth conditions), and agronomic manipulation (different land management conditions). Moreover, it is timeconsuming and involves high costs due to sequencing. These limitations can be overcome by adopting a promising molecular method for the identification or delimitation of fungal species. One such method is high-resolution melting PCR (HRM-PCR) which screens sequence variations within amplicons by analyzing the melting temperature of the double-stranded DNA (Reed and Wittwer 2004; Erali et al. 2008; Erali and Wittwer 2010; Tahmasebi et al. 2018). In recent years, HRM-PCR has been applied for determining clinically important fungal species, such as Candida spp. and Mucorales spp. (Hrncirova et al. 2010; Decat et al. 2013; Didehdar et al. 2016; Lu et al. 2017), and for identifying and distinguishing Fusarium oxysporum species complex and Aspergillus section Nigri (Ganopoulos et al. 2012; Xanthopoulou et al. 2019).

In the present study, we attempted to develop the HRMPCR assay for identifying the wheat endosphere-associated fungi based on differences in the melt profile of the ITS region of rDNA.

\section{Materials and methods}

\section{Endophytic fungi isolation and maintenance}

Endophytic fungi used in the study were isolated from roots, stems, leaves, and seeds of wheat plants cultivated in the experimental fields belonging to the Institute of Plant Genetics of the Polish Academy of Sciences in Cerekwica (Western Poland; GPS coordinates: N 52.521012, E 16.692005). A total of nine bread wheat cultivars were analyzed, which included one spring cultivar (Bombona developed by Danko Plant Breeding Ltd. Co. (Poland) and eight winter cultivars (Legenda developed by Poznań Plant Breeders Ltd., Kilimanjaro and Olivin developed by RAGT Semences Ltd. (France), Arina developed by The Swiss Federal Research
Institute Changins (RAC) (Switzerland), Artist and Patras developed by Saaten Union Ltd. (Germany), Michigen Amber deposited by Plant Breeding and Acclimatization Institute (Poland), and Fregata developed by Strzelce Plant Breeding Ltd. Co. (Poland)). These plants were collected at the late milk stage (BBCH 77), placed separately in paper bags, transported to the laboratory in chilled conditions, and stored at $4{ }^{\circ} \mathrm{C}$ before processing. Within $24 \mathrm{~h}$ of sampling, the leaves, roots, and stems were removed from the plants and sectioned into 4to $5-\mathrm{cm}$ pieces. Seeds were threshed manually, following which seed coats were also removed. All plant fragments were surface-sterilized with $70 \%$ alcohol and $0.5 \%$ active chlorine and rinsed five times in sterile distilled water. Roots, stems, and leaves were cut with a sterile scalpel, and sections measuring $1 \mathrm{~cm}$ were prepared. Seeds were cut with a sterile scalpel along the crease. Then, sterilized sections of the plant organs were transferred to Potato Dextrose Agar (PDA; Oxoid $^{\mathrm{TM}}$, Thermo Fisher Scientific, Waltham, MA, USA) supplemented with $50 \mathrm{mg} \mathrm{mL}^{-1}$ ampicillin and incubated at $23^{\circ} \mathrm{C}$ for $1-4$ weeks or until the appearance of mycelia. After incubation, putative fungal colonies were purified by subculturing three times on PDA, and then on Synthetischer Nährstoffarmer Agar (SNA; Nirenberg 1976), until visually (based on microscopic observation using a light microscope (Zeiss)) homogeneous cultures were obtained. The pure cultures were stored in tubes containing SNA at $4{ }^{\circ} \mathrm{C}$ as a working collection. For long-term preservation and in cryogenic tubes containing $20 \%$ glycerol in water $(\mathrm{v} / \mathrm{v})$ at $-80^{\circ} \mathrm{C}$.

\section{Identification of endophytic fungal isolates}

The obtained fungal isolates were subjected to morphological and molecular-based identification. The endophytic fungi grown on PDA were studied for their culture characteristics. Microscopic analysis of morphological features was evaluated in the cultures grown on SNA by using a light microscope (Zeiss). Molecular identification was carried out based on the sequencing of the internal transcribed spacer (ITS1, 5.8S, ITS2) regions of rDNA and a fragment of the translation elongation factor 1-alpha (TefI) gene, and also based on the sequencing of partial beta-tubulin $2(\beta t u b)$ gene depending on the fungal genus. DNA was extracted from the lyophilized mycelium of the isolates that were grown previously on the PDA medium using Wizard ${ }^{\circledR}$ Genomic DNA Purification Kit (Promega, Madison, WI, USA). The target regions of rDNA ITS were amplified by the primer sets ITS4 and ITS5 (White et al. 1990), of the Tef1 gene was amplified by the primer sets Ef728M (Druzhinina and Kubicek 2005) and Tef1R (Kullnig-Gradinger et al. 2002), and of the $\beta t u b$ gene using primers pairs Bt2a and Bt $2 b$ (Glass and Donaldson 1995). The PCR analysis and electrophoresis were carried out under the conditions as described by Błaszczyk et al. (2016) using modification of annealing at $62{ }^{\circ} \mathrm{C}$ for the $\beta$ tub gene fragment. Visibly clear PCR products were purified 
Table 1 Wheat endogenous fungal strains used in the HRM-PCR analysis

\begin{tabular}{|c|c|c|}
\hline Culture/strain code & NCBI GenBank accession no. & Genus \\
\hline MK31 & MT111904 & \multirow[t]{7}{*}{ Epicoccum $\mathrm{sp}$. } \\
\hline MK50 & MT111906 & \\
\hline MK169 & MT111910 & \\
\hline MK138 & MT111907 & \\
\hline MK155 & MT111909 & \\
\hline MK146 & MT111908 & \\
\hline MK41 & MT111905 & \\
\hline MK218 & MT111925 & \multirow[t]{7}{*}{ Alternaria sp. } \\
\hline MK141 & MT111922 & \\
\hline MK168 & MT111923 & \\
\hline MK136 & MT111921 & \\
\hline MK37 & MT111919 & \\
\hline MK35 & MT111918 & \\
\hline MK40 & MT111920 & \\
\hline MK133 & MT112063 & \multirow[t]{4}{*}{ Penicillium sp. } \\
\hline MK164 & MT112067 & \\
\hline MK162 & MT112066 & \\
\hline MK158 & MT112065 & \\
\hline MK180 & MT111898 & \multirow[t]{3}{*}{ Trichoderma sp. } \\
\hline MK197 & MT111900 & \\
\hline MK175 & MT111897 & \\
\hline MK47 & MT111933 & \multirow[t]{7}{*}{ Fusarium sp. } \\
\hline MK54 & MT111934 & \\
\hline MK174 & MT111937 & \\
\hline MK107 & MT111935 & \\
\hline MK221 & MT111939 & \\
\hline MK121 & MT111936 & \\
\hline MK176 & MT111938 & \\
\hline
\end{tabular}

according to the procedure described by Gromadzka et al. (2019). The sequencing reactions of ITS, Tefl, and $\beta t u b$ amplicons were carried out using the ABI Prism BigDye Terminator Cycle Sequencing Ready Reaction Kit (Applied Biosystems, Switzerland) in accordance with the supplier's instructions. Following sequencing reactions, reads were performed at the Sequencing Laboratory in the Institute of Biochemistry and Biophysics in Warsaw. The sequences were edited and assembled using the Chromas software (version 1.43, 2004; Technelysium Pty Ltd, South Brisbane, QLD, Australia) and subsequently idenifed by BLASTn analysis (NCBI, http://blast.ncbi.nlm.nih.gov/). In order to determine unique ITS haplotypes, the ITS sequences were first aligned using the ClustalW program (Thompson et al. 1994), and those exhibiting identical alleles in the ITS locus were grouped together. From each group (ITS haplotype), at least one sequence was chosen and deposited in the NCBI GenBank database. The accession numbers are detailed in Table 1.

\section{HRM-PCR procedure}

HRM-PCRs were performed using a Bio-Rad CFX RealTime PCR Thermocycler (Bio-Rad, Poland). The total volume of $10 \mu \mathrm{L}$ contained $1 \mathrm{ng}$ of genomic DNA, $5 \mathrm{pM}$ of each primer, and $5 \mu \mathrm{L}$ of the reaction mixture with EvaGreen dye (SSoFast Supermix; Bio-Rad). The condition of the HRMPCR reaction were as follows: initial denaturation at $98{ }^{\circ} \mathrm{C}$ for $5 \mathrm{~min}$, which was followed by 30 cycles of denaturation $\left(98^{\circ} \mathrm{C}\right.$ for $\left.15 \mathrm{~s}\right)$, annealing $\left(56^{\circ} \mathrm{C}\right.$ for $\left.15 \mathrm{~s}\right)$, and extension $(70$ ${ }^{\circ} \mathrm{C}$ for $60 \mathrm{~s}$ ); this study. For the analysis of melting curve, at the end of the amplification, one additional cycle was performed, starting with $70{ }^{\circ} \mathrm{C}$ for $2 \mathrm{~s}$, following which the
Fig. 1 The number of wheat endophytic isolates by identified fungal genera

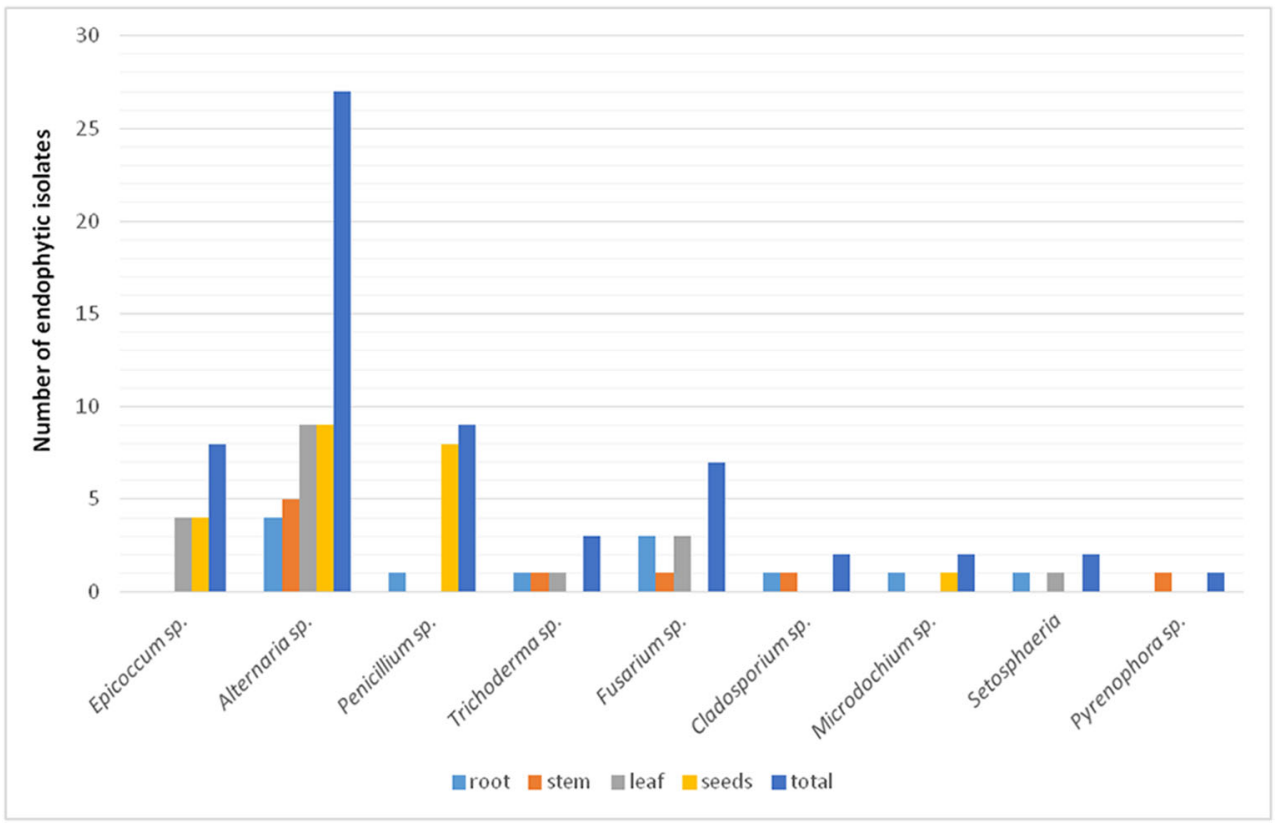


Table 2 Comparison of melting points

Genus

Melting temperature $\left({ }^{\circ} \mathrm{C}\right)$

Epicoccum sp.

Alternaria sp.

Penicillium sp.

Trichoderma sp.

Fusarium sp.
80.4-80.6

$80.8-81.0$

81.2

$80.2-80.4$

$79.8-80.2$ temperature was subsequently increased to $95^{\circ} \mathrm{C}$ in $0.2^{\circ} \mathrm{C} \mathrm{s}^{-1}$ increments (HRM analyses). Data evaluation was carried out using the Bio-Rad CFX Manager Software version 1.6 and Bio-Rad Precision Melt Analysis Software version 1.1. Then, universal primers were constructed for ITS, specifically the ITS of rDNA, (ITSf 5'-AACTTTCAACAACGGATCTC-3' and ITSr 5'-AAATGACGCTCGAACAGGCA-3'), and used in the study. The generated amplicons were $160 \mathrm{pb}$ in length.
Fig. 2 Differentiation of the fungal strains. a Genotyping of five fungal genera using HRM analysis. $\mathbf{b}$ Calculation of the relative ratio between the temperatures
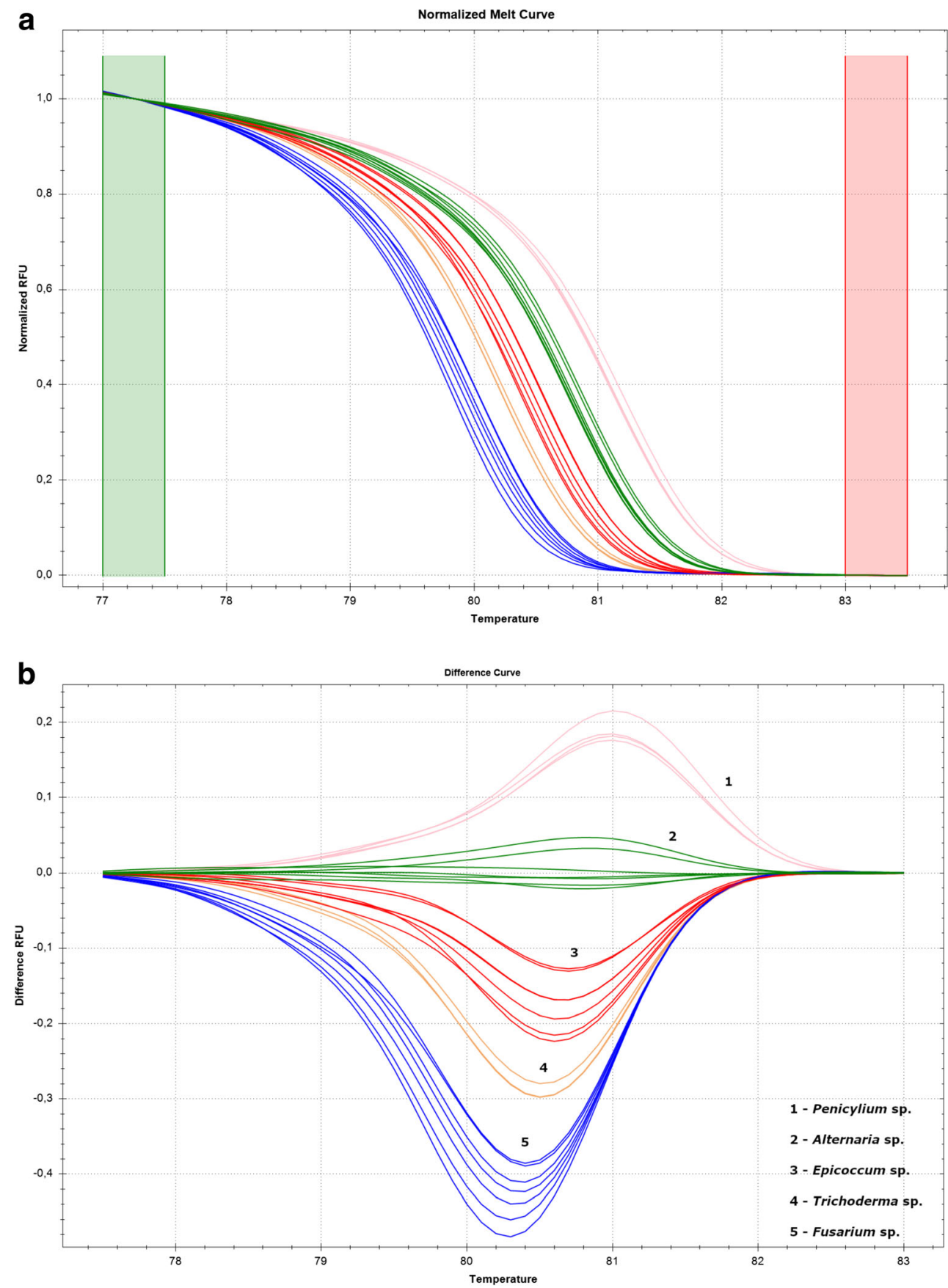


\section{Phylogenetic analyses}

In order to confirm the results of HRM-PCR, to construct a phylogenetic tree, the analyzed sequences were used. The evolutionary history was inferred using the Neighbor-Joining method (Saitou and Nei 1987). The optimal tree had a sum of branch length equal to 1.27991273 . The tree was drawn to scale, with branch lengths in the same units as those of the evolutionary distances that were used to infer the phylogenetic tree. The evolutionary distances were computed using the maximum composite likelihood method (Tamura et al. 2013) and are expressed as the number of base substitutions per site. The phylogenetic analysis involved 28 nucleotide sequences. The codon positions included were $1 \mathrm{st}+2 \mathrm{nd}+3 \mathrm{rd}+$ noncoding. All ambiguous positions were removed for each sequence pair (pairwise deletion option). The final dataset had a total of 573 positions. Evolutionary analyses were conducted using the MEGA X software (Kumar et al. 2018).

\section{Results and discussion}

Overall 61 endophytic fungal isolates were obtained from all the tested wheat cultivars and plant organs (Fig. 1). They were identified by morphological characteristics, microscopic analysis, and data sequencing. Alternaria, Penicillium, Epicoccum, Fusarium, and Trichoderma were among the common genera present. These fungal genera have already been described as the endophytes of wheat by various authors (Crous et al. 1995; Larran et al. 2002; Comby et al. 2016). Therefore, strains belonging to these genera, representing each of the identified ITS haplotypes, were selected for the HRMPCR analysis in the present study. As shown in Fig. 1, the genera that were represented by only individual isolates were Cladosporium, Microdochium, Setosphaeria, and Pyrenophora. Most of them were isolated from the inner tissue of wheat in the previous works (Crous et al. 1995; Comby et al. 2016). However, in the present study, these genera were excluded from the HRM-PCR analysis due to their low representativeness.

The fungal strains selected for the HRM-PCR analysis are listed in Table 1. All the samples obtained from the selected strains were amplified using the EvaGreen dye-based method using a Bio-Rad CFX Thermocycler. The specificities of the melting peaks $\left(T_{\mathrm{m}}\right)$ were determined using the HRM analyses, which allowed differentiating the investigated ITS haplotypes of fungal strains. Thus, it was possible to distinguish the abovementioned fungal genera: Epicoccum, Alternaria, Penicillium, Trichoderma, and Fusarium. All strains were represented by a peak ranging from 79.8 to $81.2^{\circ} \mathrm{C}$ (Table 2).

Furthermore, in this study, we differentiated the tested fungal genera by analyzing the shape of the melting curves (Fig. 2).

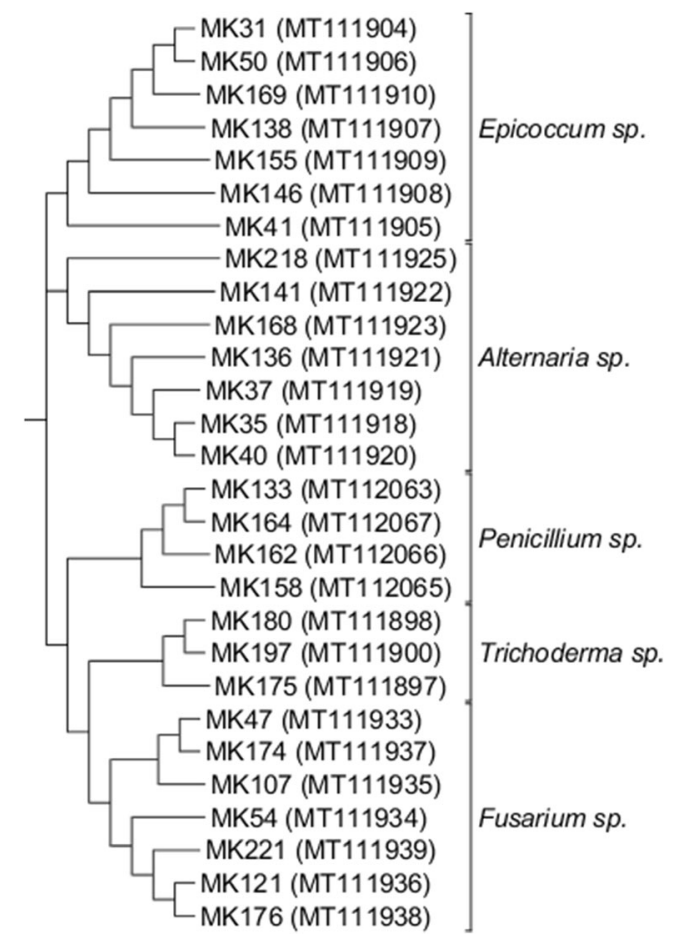

Fig. 3 A phylogenetic tree constructed based on the analyzed ITS sequences. The numbers indicate the DNA samples of different fungi

In addition, the phylogenetic tree, which was constructed based on the sequences of the tested fungal strains, confirmed that the samples belonged to different clades (Fig. 3).

Thus far, several studies have employed the HRM technique to develop a molecular approach for the identification and discrimination of clinically relevant fungal species (Hrncirova et al. 2010; Decat et al. 2013; Didehdar et al. 2016; Lu et al. 2017), for monitoring the composition of the indoor airborne fungal contaminants (Libert et al. 2017), or for the identification of phytopathogenic fungi (Papavasileiou et al. 2016). Currently, a number of studies are focusing on exploring the wheat mycobiome (Comby et al. 2016; Gdanetz and Trail 2017) and acquiring fungal endophytes that might be beneficial to the host plant (Gdanetz and Trail 2017). The approach used in these studies indicates that it is possible to improve culture-dependent methods to identify the wheat endosphere-associated fungi. In comparison with other highthroughput technologies, such as next-generation sequencing, HRM-PCR analysis is advantageous because it is faster, simpler, and cost-effective and can accurately screen a large number of samples. Therefore, the application of this novel method for the differentiation of endophytic fungi could contribute not only to the rapid identification of new endophytes that are beneficial to plants but also to a better understanding of the complexity and diversity of the native fungal communities that are associated with the wheat endosphere. 


\section{Conclusion}

This study showed that HRM and curve analyses might be applied for large-scale screening of the cultured endophytic fungi. The universal ITS primers constructed in the study were able to distinguish five fungal genera. Real-time HRM-PCR is a cheap, sensitive, precize, and rapid assay that enables the differentiation of fungal genus. Furthermore, with the use of some standardized sequences, it allows screening a large group of isolates without sequencing fragments of ITS.

Funding information This study was partially (isolation and molecular identification of the endophytic fungi) funded by the National Science Centre (Poland) (project no. 2017/27/B/NZ9/01591).

\section{Compliance with Ethical Standards}

Conflict of interest The authors declare that they have no conflict of interest.

Ethical approval This article does not contain any studies with human participants or animals performed by any of the authors.

Open Access This article is licensed under a Creative Commons Attribution 4.0 International License, which permits use, sharing, adaptation, distribution and reproduction in any medium or format, as long as you give appropriate credit to the original author(s) and the source, provide a link to the Creative Commons licence, and indicate if changes were made. The images or other third party material in this article are included in the article's Creative Commons licence, unless indicated otherwise in a credit line to the material. If material is not included in the article's Creative Commons licence and your intended use is not permitted by statutory regulation or exceeds the permitted use, you will need to obtain permission directly from the copyright holder. To view a copy of this licence, visit http://creativecommons.org/licenses/by/4.0/.

\section{References}

Blaalid R, Kumar S, Nilsson RH et al (2013) ITS1 versus ITS2 as DNA metabarcodes for fungi. Mol Ecol Resour 13:218-224. https://doi. org/10.1111/1755-0998.12065

Błaszczyk L, Strakowska J, Chełkowski J et al (2016) Trichoderma species occurring on wood with decay symptoms in mountain forests in Central Europe: genetic and enzymatic characterization. J Appl Genet 57:397-407. https://doi.org/10.1007/s13353-015-0326-1

Colla G, Rouphael Y, Bonini P, Cardarelli M (2015) Coating seeds with endophytic fungi enhances growth, nutrient uptake, yield and grain quality of winter wheat. Int J Plant Pro 9(2):171-189

Comby M, Lacoste S, Baillieul F et al (2016) Spatial and temporal variation of cultivable communities of co-occurring endophytes and pathogens in wheat. Front Microbiol 7. https://doi.org/10.3389/ fmicb.2016.00403

Crous PW, Petrini O, Marais GF et al (1995) Occurrence of fungal endophytes in cultivars of Triticum aestivum in South Africa. Mycoscience 36:105-111. https://doi.org/10.1007/BF02268579

Decat E, Van Mechelen E, Saerens B et al (2013) Rapid and accurate identification of isolates of Candida species by melting peak and melting curve analysis of the internally transcribed spacer region 2 fragment (ITS2-MCA). Res Microbiol 164:110-117. https://doi. org/10.1016/j.resmic.2012.10.017

Díaz Herrera S, Grossi C, Zawoznik M, Groppa MD (2016) Wheat seeds harbour bacterial endophytes with potential as plant growth promoters and biocontrol agents of Fusarium graminearum. Microbiol Res 186-187:37-43. https://doi.org/10.1016/j.micres.2016.03.002

Didehdar M, Khansarinejad B, Amirrajab N, Shokohi T (2016) Development of a high-resolution melting analysis assay for rapid and high-throughput identification of clinically important dermatophyte species. Mycoses 59:442-449. https://doi.org/10.1111/myc. 12492

Druzhinina I, Kubicek CP (2005) Species concepts and biodiversity in Trichoderma and Hypocrea : from aggregate species to species clusters? J Zhejiang Univ (Sci) 6B:100-112. https://doi.org/10. 1631/jzus.2005.B0100

Erali M, Wittwer CT (2010) High resolution melting analysis for gene scanning. Methods 50:250-261. https://doi.org/10.1016/j.ymeth. 2010.01.013

Erali M, Voelkerding KV, Wittwer CT (2008) High resolution melting applications for clinical laboratory medicine. Exp Mol Pathol 85: 50-58. https://doi.org/10.1016/j.yexmp.2008.03.012

Ganopoulos I, Madesis P, Zambounis A, Tsaftaris A (2012) Highresolution melting analysis allowed fast and accurate closed-tube genotyping of Fusarium oxysporum formae speciales complex. FEMS Microbiol Lett 334:16-21. https://doi.org/10.1111/j.15746968.2012.02610.x

Gdanetz K, Trail F (2017) The wheat microbiome under four management strategies, and potential for endophytes in disease protection. Phytobiomes 1:158-168. https://doi.org/10.1094/PBIOMES-05-170023-R

Glass NL, Donaldson GC (1995) Development of primer sets designed for use with the PCR to amplify conserved genes from filamentous ascomycetes. Appl Environ Microbiol 61:1323-1330. https://doi. org/10.1128/AEM.61.4.1323-1330.1995

Gromadzka K, Błaszczyk L, Chełkowski J, Waśkiewicz A (2019) Occurrence of mycotoxigenic fusarium species and competitive fungi on preharvest maize ear rot in Poland. Toxins 11:224. https://doi. org/10.3390/toxins 11040224

Hrncirova K, Lengerova M, Kocmanova I et al (2010) Rapid detection and identification of mucormycetes from culture and tissue samples by use of high-resolution melt analysis. J Clin Microbiol 48:33923394. https://doi.org/10.1128/JCM.01109-10

Hubbard M, Germida J, Vujanovic V (2012) Fungal endophytes improve wheat seed germination under heat and drought stress. Botany 90: 137-149. https://doi.org/10.1139/b11-091

Hubbard M, Germida JJ, Vujanovic V (2014) Fungal endophytes enhance wheat heat and drought tolerance in terms of grain yield and second-generation seed viability. J Appl Microbiol 116:109-122. https://doi.org/10.1111/jam.12311

Istifadah N, McGee PA (2006) Endophytic Chaetomium globosum reduces development of tan spot in wheat caused by Pyrenophora tritici-repentis. Australas Plant Pathol 35:411. https://doi.org/10. 1071/AP06038

Keyser CA, Jensen B, Meyling NV (2016) Dual effects of Metarhizium spp. and Clonostachys rosea against an insect and a seed-borne pathogen in wheat: dual effects of Metarhizium spp. and Clonostachys rosea. Pest Manag Sci 72:517-526. https://doi.org/ $10.1002 /$ ps.4015

Kullnig-Gradinger CM, Szakacs G, Kubicek CP (2002) Phylogeny and evolution of the genus Trichoderma: a multigene approach. Mycol Res 106:757-767. https://doi.org/10.1017/S0953756202006172

Kumar S, Stecher G, Li M et al (2018) MEGA X: Molecular evolutionary genetics analysis across computing platforms. Mol Biol Evol 35: 1547-1549. https://doi.org/10.1093/molbev/msy096 
Larran S, Perelló A, Simón MR, Moreno V (2002) No title found. World J Microbiol Biotechnol 18:683-686. https://doi.org/10.1023/A: 1016857917950

Lenc L, Kwaśna H, Sadowski C, Grabowski A (2015) Microbiota in wheat roots, rhizosphere and soil in crops grown in organic and other production systems. J Phytopathol 163:245-263. https://doi. org/10.1111/jph. 12313

Libert X, Packeu A, Bureau F et al (2017) Discrimination of three genetically close Aspergillus species by using high resolution melting analysis applied to indoor air as case study. BMC Microbiol 17: 84. https://doi.org/10.1186/s12866-017-0996-4

Lu S, Mirchevska G, Phatak SS et al (2017) Dynamic time warping assessment of high-resolution melt curves provides a robust metric for fungal identification. PLoS One 12:e0173320. https://doi.org/10. 1371/journal.pone. 0173320

Papavasileiou A, Madesis PB, Karaoglanidis GS (2016) Identification and differentiation of Monilinia species causing brown rot of pome and stone fruit using high-resolution melting (HRM) analysis. Phytopathology 106:1055-1064. https://doi.org/10.1094/PHYTO01-16-0016-R

Reddy GVP, Tangtrakulwanich K, Wu S et al (2014) Evaluation of the effectiveness of entomopathogens for the management of wireworms (Coleoptera: Elateridae) on spring wheat. J Invertebr Pathol 120:43-49. https://doi.org/10.1016/j.jip.2014.05.005

Reed GH, Wittwer CT (2004) Sensitivity and specificity of singlenucleotide polymorphism scanning by high-resolution melting analysis. Clin Chem 50:1748-1754. https://doi.org/10.1373/clinchem. 2003.029751

Rodriguez RJ, White JF Jr, Arnold AE, Redman RS (2009) Fungal endophytes: diversity and functional roles: Tansley review. New Phytol 182:314-330. https://doi.org/10.1111/j.1469-8137.2009. 02773.x
Saitou N, Nei M (1987) The neighbor-joining method: a new method for reconstructing phylogenetic trees. Mol Biol Evol 4:406-425

Schoch CL, Seifert KA, Huhndorf S et al (2012) Nuclear ribosomal internal transcribed spacer (ITS) region as a universal DNA barcode marker for fungi. Proc Natl Acad Sci U S A 109:6241-6246

Tahmasebi H, Dehbashi S, Arabestani MR (2018) High resolution melting curve analysis method for detecting of carbapenemases producing pseudomonas aeruginosa. 7(4):70-77

Tamura K, Stecher G, Peterson D et al (2013) MEGA6: Molecular evolutionary genetics analysis version 6.0. Mol Biol Evol 30:27252729. https://doi.org/10.1093/molbev/mst197

Thompson JD, Higgins DG, Gibson TJ (1994) CLUSTAL W: improving the sensitivity of progressive multiple sequence alignment through sequence weighting, position-specific gap penalties and weight matrix choice. 22(22): 4673-4680

Trnka M, Rötter RP, Ruiz-Ramos M et al (2014) Adverse weather conditions for European wheat production will become more frequent with climate change. Nat Clim Chang 4:637-643. https://doi.org/10. 1038/nclimate2242

White TJ, Bruns T, Lee S, Taylor J (1990) Amplification and direct sequencing of fungal ribosomal RNA genes for phylogenetics. In: PCR Protocols. Elsevier, pp 315-322. https://doi.org/10.1016/b9780-12-372180-8.50042-1

Xanthopoulou A, Ganopoulos I, Tryfinopoulou P et al (2019) Rapid and accurate identification of black aspergilli from grapes using high resolution melting (HRM) analysis. J Sci Food Agric 99:309-314. https://doi.org/10.1002/jsfa.9189

Publisher's note Springer Nature remains neutral with regard to jurisdictional claims in published maps and institutional affiliations. 